J. Nepal Chem. Soc., Vol. 36, 2017

\title{
Characterization of the Supari Nut-Based Activated Carbon for Adsorption of Fluoride
}

\author{
Sahira Joshi ${ }^{1}$ and Puspalal Homagai ${ }^{2 *}$ \\ ${ }^{1}$ Department of Engineering science and Humanities \\ Institute of Engineering, Tribhuvan University, Lalitpur, Nepal \\ ${ }^{2}$ Amrit Campus, Tribhuvan University, Thamel, Kathmandu, Nepal \\ Email: homagaipl@gmail.com
}

\begin{abstract}
Activated carbon (AC) was prepared from Supari nut by chemical activation at $400{ }^{\circ} \mathrm{C}$ using $\mathrm{H}_{3} \mathrm{PO}_{4}$ as activating agent under $N_{2}$ atmosphere. The prepared activated carbon (AC) was characterized by Iodine number $\left(I_{N}\right)$, Methylene blue number $\left(M B_{N}\right)$, scanning electron Microscopy (SEM) and Fourier Transform infrared spectroscopy (FTIR). The AC showed relatively higher $I_{N}, M B_{N}$ and surface area of $888 \mathrm{mg} / \mathrm{gm}, 369 \mathrm{mg} / \mathrm{gm}$ and $936 \mathrm{~m}^{2} / \mathrm{gm}$ respectively. These values are comparable to commercial AC. It indicated the presence of a large amount of micro and mesopores in the AC. As shown by SEM image, the $A C$ is highly porous in nature. FTIR spectra indicated that, the AC contains oxygenated functional groups such as -OH, -CO groups. The results from Boehm titration showed that, the AC surface contains higher amount of acidic surface functional groups such as carboxyl, phenolic and lactonic. The AC was modified as adsorbents by compositing it with $\mathrm{Al}_{2} \mathrm{O}_{3}$ and $\mathrm{Fe}_{2} \mathrm{O}_{3}$ separately. The percentage adsorption (\%) of $\mathrm{Al}_{2} \mathrm{O}_{3} / \mathrm{AC}$ composite and $\mathrm{Fe}_{2} \mathrm{O}_{3} / \mathrm{AC}$ composite for fluoride was found to be $74.5 \%$ and $60.16 \%$ respectively. Among the two adsorbents, $\mathrm{Al}_{2} \mathrm{O}_{3}$ S Supari AC composite showed high percentage of fluoride adsorption so it could be efficient adsorbent for removal of fluoride from water.
\end{abstract}

Keywords: Activated carbon, Supari nut AC/composite, adsorption, fluoride.

\section{Introduction}

Fluoride is a trace mineral that is necessary for forming and maintaining healthy bones and teeth. However, it has long been known that, excessive fluoride intake can lead to dental and skeletal fluorosis in human beings. The primary source of fluoride intake is through drinking water. The permissible limit of fluoride in drinking water is $1.5 \mathrm{mg} / \mathrm{L}$ as suitable for human consumption ${ }^{1}$.

Groundwater has emerged as the major source of water supply for drinking purposes in recent years. People living in more than 25 nations around the world consume water with fluoride concentration above permissible limit ${ }^{1}$. In Nepal, excessive fluoride concentrations have been reported in groundwater of Terai region (Low land of Nepal). However, to date, no specific study has yet been undertaken regarding fluoride contamination in groundwater of that region ${ }^{2}$. More than half of the total population of the country lives in Terai region and $90 \%$ of them depends in on groundwater for their drinking water

\footnotetext{
* Corresponding author
} 
supply ${ }^{3}$. Since ingestion of high level of fluoride has an adverse effect to human health it is essential to remove fluoride from groundwater before consumption.

Adsorption is considered as one of the most effective and promising method for fluoride removal of low concentration in water. Various adsorbents such as activated carbon $^{4}$, activated alumina ${ }^{5}$, bone charcoal $^{6}$ and various metal oxides ${ }^{7}$ etc have been explored for removal of fluoride from water. Activated carbon is among the most frequently used adsorbent for fluoride removal. The adsorption capacity of AC is due to high surface area, well developed pore structure and presence of surface functional groups. The pores of AC are classified in three groups: micropores (diameter $<2) \mathrm{nm}$, mesopores $(2 \mathrm{~nm}<$ diameter $<$ $50 \mathrm{~nm}$ ), and even macropore (diameter $>50 \mathrm{~nm}$ ), according to the International Union of Pure and Applied Chemistry ${ }^{8}$. The porous texture of the activated carbons depends strongly on both, the activation process and the nature of the precursor.

In recent years, the interest in fluoride removal by AC derived from agricultural waste is growing due to their low cost and availability. ACs from various agricultural wastes have been reported for fluoride removal such as coconut shell ${ }^{9}$, olive stone ${ }^{10}$, Lapsi seed stone ${ }^{4}$ etc. The absorption capacity of fluoride with plain $\mathrm{AC}$ were rather poor, but can be improved by chemical modification. Fluoride has strong affinity toward multivalent metal ions like $\mathrm{Al}^{3+}, \mathrm{Fe}^{3+}, \mathrm{Ca}^{2+}, \mathrm{Zr}^{4+}$ etc due of the high electronegativity and small ionic size. Therefore, functionalization and subsequent incorporation of these ions on AC matrix will produce a good adsorbent. Recently, use of composite materials prepared by incorporation of thsese metal compounds in the $\mathrm{AC}$ matrix have been increased due to its unique structure and properties. Accordingly, several composite adsorbent including Carbon/Pottery Composite ${ }^{11}$, alumina supported carbon composite $^{12}$, for fluoride removal of water have been reported.

Different parts of Supari (Areca Catechu) nut plant had been used for the preparation of AC for various applications such as Betel nut $\operatorname{coir}^{13}$, Areca nut $\operatorname{pod}^{14}$ and Areca nut shell ${ }^{15}$. However, there no report on the utilization of itself for preparation of $\mathrm{AC}$ for removal of fluoride from water. Hence the present study deals with preparation and characterization of AC prepared from Supari nut for adsorption of fluoride from water.

\section{Experimental Methods}

\section{Preparation of carbon}

Supari nuts were washed with distilled water and dried in oven at $110^{\circ} \mathrm{C}$ for $24 \mathrm{hrs}$. The nuts were crushed, grounded with mortar and electric grinder. The crushed particles were then sieved to obtain the fraction of size $312 \mu \mathrm{m} .20 \mathrm{gm}$ of powdered Supari nut was mixed with $\mathrm{H}_{3} \mathrm{PO}_{4}$ in the ratio of 1:1 by weight and, stirred with glass rod at $70^{\circ} \mathrm{C}$ until partially dried. The sample was kept in an oven at $100^{\circ} \mathrm{C}$ for overnight. The mixture was then carbonized in a horizontal tubular furnace at $400^{\circ} \mathrm{C}$ under a flow $(75$ $\mathrm{ml} / \mathrm{min}$ ) of $\mathrm{N}_{2}$ for 3 hours. After cooling, the activated carbon was treated with $1 \% \mathrm{NaHCO}_{3}$ solution and then washed with warm distilled water until it became neutral. The $\mathrm{AC}$ was dried in an oven maintained at a temperature of $110^{\circ} \mathrm{C}$ for 24 hours. The dried $\mathrm{AC}$ sample were grounded and sieved to get to the fraction of size $112 \mu \mathrm{m}$. 


\section{J. Nepal Chem. Soc., Vol. 36, 2017}

For the preparation of plain carbon, $30 \mathrm{~g}$ of dried, crushed and grounded Supari nuts was pyrolyzed at $400{ }^{\circ} \mathrm{C}$ under a continuous flow of nitrogen gas for $3 \mathrm{hrs}$. The carbon was washed, dried and grounded into powder. The prepared carbons were used for advanced characterization and application studies.

\section{Characterization}

Characterizations of ACs were performed by determining iodine number $\left(\mathrm{I}_{\mathrm{N}}\right)$, methylene blue number $\left(\mathrm{MB}_{\mathrm{N}}\right)$, Scanning electron microscopy (SEM), Fourier and Transform-Infrared (FTIR) spectroscopy. Iodine number of ACs was determined according to ASTM D4607-94 method ${ }^{16}$. Methylene blue number of ACs was determined by single point adsorption isotherm studies according to Standard Method ${ }^{17}$. Surface area of $\mathrm{AC}$ was estimated by $\mathrm{I}_{\mathrm{N}}$ and $\mathrm{MB}_{\mathrm{N}}$ using multiple regressions ${ }^{18}$. Surface morphology of the AC was studied using scanning electron microscope U-8000, Hitachi Co. Ltd. Japan. Presence of surface functional groups of the AC was determined by recording FTIR spectra on the Thermo Electron Corporation, Nicolet 4700 at room temperature. The $\%$ of transmission of samples was recorded over $500-4000 \mathrm{~cm}^{-1}$. The amount of acidic surface functional groups in the AC was determined by Boehm titration method $^{19}$.

\section{Preparation of Adsorbent}

Adsorbent was prepared by compositing the $\mathrm{AC}$ with $\mathrm{Fe}_{2} \mathrm{O}_{3}$ and $\mathrm{Al}_{2} \mathrm{O}_{3}$. For the preparation of $\mathrm{Al}_{2} \mathrm{O}_{3} / \mathrm{AC}$ composite, $36.8 \mathrm{gm}$ of aluminum nitrate $\left(\mathrm{Al}\left(\mathrm{NO}_{3}\right)_{3} \cdot 9 \mathrm{H}_{2} \mathrm{O}\right) \mathrm{gm}$ was dissolved in $400 \mathrm{ml}$. distilled water and $5 \mathrm{gm} \mathrm{AC}$ was added. Then, $5 \mathrm{M} \mathrm{NaOH}$ was added drop wise till the precipitation of $\mathrm{Al}(\mathrm{OH})_{3}$ was completed. The product was dried in oven at $110^{\circ} \mathrm{C}$ for $12 \mathrm{hrs}$, calcined in tube furnace at $300{ }^{\circ} \mathrm{C}$ for an hour. $\mathrm{Fe}_{2} \mathrm{O}_{3} / \mathrm{AC}$ composite was prepared according to the procedure ${ }^{20} .2$ grams of $\mathrm{AC}$ was added to $8 \mathrm{~mL}$ of $2 \mathrm{M} \mathrm{Fe}\left(\mathrm{NO}_{3}\right)_{3} \cdot 9 \mathrm{H}_{2} \mathrm{O}$ solution, then $0.1 \mathrm{~mL} 10 \mathrm{M}$ sodium hydroxide was until the precipitation of $\mathrm{Fe}(\mathrm{OH})_{3}$ was completed. The mixture was heated at $105^{\circ} \mathrm{C}$ overnight. Then, the prepared composites were washed with distilled water till it became neutral, dried at $100{ }^{\circ} \mathrm{C}$ for $24 \mathrm{hrs}$, sieved to obtain a particle size of $212 \mu \mathrm{m}$.

\section{Adsorption Experiments}

A definite amount of adsorbents was suspended with $50 \mathrm{ml}$ of fluoride solution separately in $100 \mathrm{ml}$ plastic conical flasks. The suspensions were being agitated on Digital Rotator at $225 \mathrm{rpm}$ at room temperature. After equilibrium, the suspension was filtered and fluoride ion concentration in the filtrate was measured. The concentration of fluoride ion in the sample was determined by using fluoride ion selective electrode (ISE) according to the procedure ${ }^{21}$. Percentage of adsorption of fluoride ions was calculated by the following equation.

$$
\text { Removal }(\%)=\frac{\left(C_{0}-C_{e}\right) \times 100}{C_{0}}
$$

Where, $C_{o}=$ initial concentration of fluoride ions $(\mathrm{mg} / \mathrm{L}) ; C_{e}=$ equilibrium concentration of fluoride ion $(\mathrm{mg} / \mathrm{L}) ; \mathrm{V}=$ volume of fluoride solution $(\mathrm{L})$ and $\mathrm{M}=$ mass of the adsorbent $(\mathrm{gm})$.

\section{Results and Discussion}

\section{Characterization of carbon}


Iodine number and methylene blue number

Iodine number, methylene blue number and surface area of carbons are shown in Figure: 1

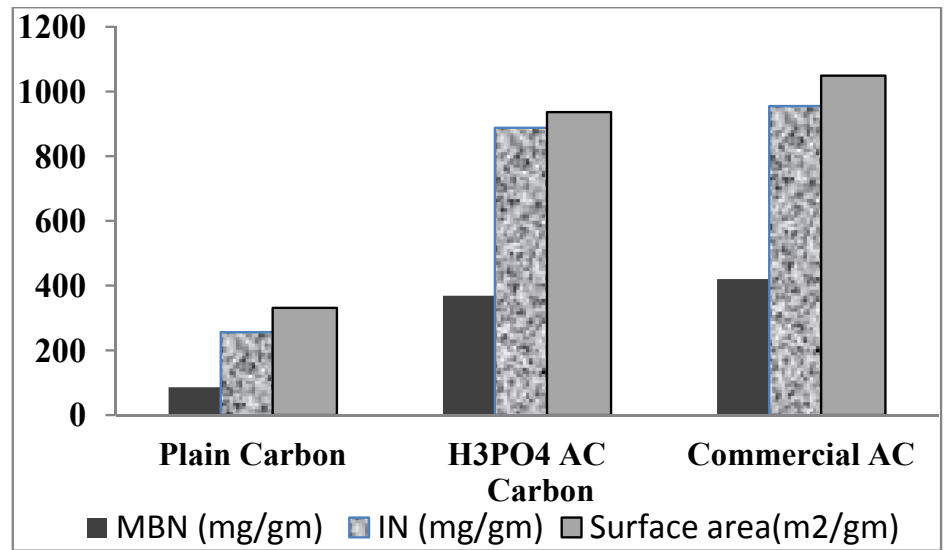

Figure1: Iodine number, methylene blue number and surface area of carbons

$\mathrm{I}_{\mathrm{N}}$ and $\mathrm{MB}_{\mathrm{N}}$ are the most important parameter used for the determination of adsorption capacity of the carbon. Iodine number is the amount of iodine adsorbed (in milligrams) by $1 \mathrm{gm}$ of carbon (Cleiton and Guerreiro, 2011). $\mathrm{I}_{\mathrm{N}}$ represents the microporous structure $(<2 \mathrm{~nm})$ of the AC relative to the amount of iodine adsorbed from solution. It indicates that, carbon preferentially adsorbs small molecules. In the same way, methylene blue number is defined as the amount of methylene blue dye adsorbed (in milligrams) by $1 \mathrm{~g}$ of carbon (Raposo et al, 2009). It measures the mesoporous structure and indicates the adsorption capacity of the carbon for medium size molecules. It represents the mesopore $(2-50 \mathrm{~nm})$ content which indicates the ability to adsorb medium size molecules. $\mathrm{I}_{\mathrm{N}}$ and $\mathrm{MB}_{\mathrm{N}}$ and surface area of $\mathrm{AC}$ were found to be $888 \mathrm{mg} / \mathrm{g}, 369 \mathrm{mg} / \mathrm{g}$ and $936 \mathrm{~m}^{2} / \mathrm{g}$ respectively which is much higher than that of plain carbon. It suggests that, the microporosity and mesoporosity in $\mathrm{AC}$ has increased by activation with $\mathrm{H}_{3} \mathrm{PO}_{4}$. These values were found to be comparable to that of commercial AC. This implies that, the microporosity, mesoporosity of AC were highly developed.

\section{Scanning electron microscopy (SEM) image}

Surface morphology of carbons was studied by Scanning Electron Microscopy (SEM). SEM images of carbons are shown in Figure: 2.

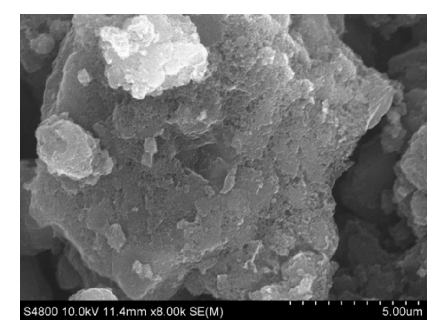

Figure 2: (A) plain carbon

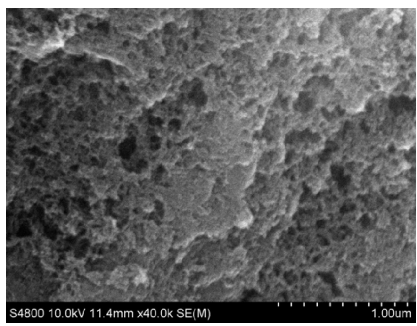

Figure 2: (B) Activated carbon

Figure 2: SEM images of the plain carbon and activated carbon

In the SEM image of plain carbon, pores are not clearly seen on the external surface while the external surface of activated carbon is filled with pores of different shape and size. The pores are resulted by activation with $\mathrm{H}_{3} \mathrm{PO}_{4}$. During activation process, $\mathrm{H}_{3} \mathrm{PO}_{4}$ combines with organic species to form 
phosphate and polyphosphate bridges. They connect and cross-link biopolymer fragments via. cyclization and condensation reactions. It results in the swelling of the carbon structure which contributes to the development of porosity.

\section{Fourier Transform Infrared (FTIR) Spectra}

FTIR spectra were collected for characterization of surface functional groups of carbons. FTIR spectra of carbons are shown in Figure: 2.

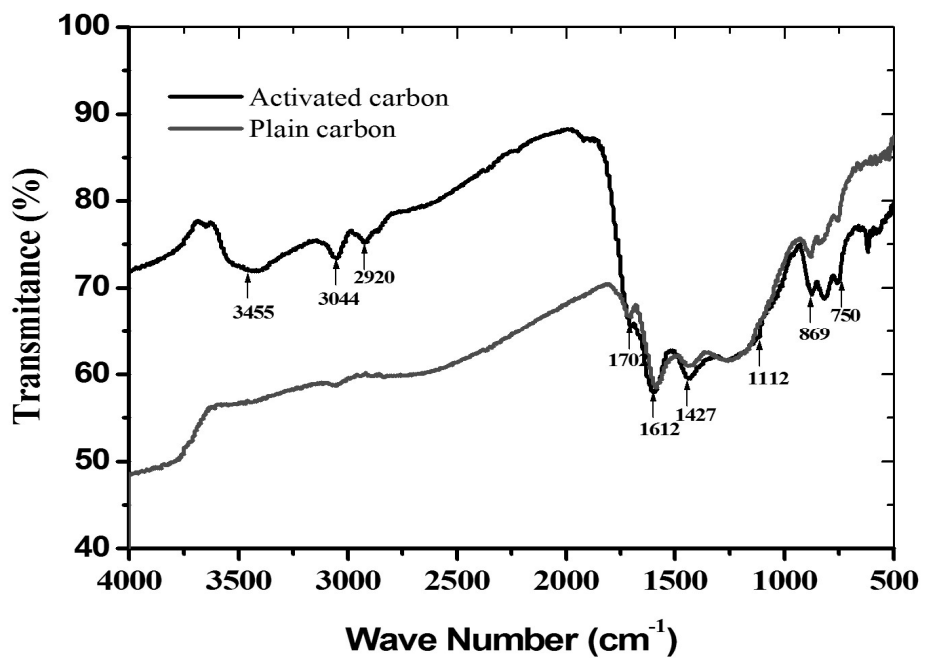

Figure 3: FTIR spectra of the plain carbon and activated carbon

FTIR spectra of plain carbon and AC were quite similar. Both carbons showed the absorption bands at the region of $3455 \mathrm{~cm}^{-1}, 1702 \mathrm{~cm}^{-1}, 11612 \mathrm{~cm}^{-1}, 1427 \mathrm{~cm}^{-1}$ and $1112 \mathrm{~cm}^{-1}$ (Figure: 2 ). A band at $3455 \mathrm{~cm}^{-}$ ${ }^{1}$ in the $\mathrm{AC}$ is assigned to $\mathrm{O}-\mathrm{H}$ stretching vibration in hydroxyl groups. However, this band is not clear in plain carbon. The weak band located at $1702 \mathrm{~cm}^{-1}$ is assigned to the stretching vibration of $\mathrm{C}=\mathrm{O}$ in ketones, aldehyde, lactone, and carboxyl ${ }^{22}$. A strong band at $1612 \mathrm{~cm}^{-1}$ and $1427 \mathrm{~cm}^{-1}$ is attributed to $\mathrm{C}=\mathrm{C}$ stretching variation in aromatic rings ${ }^{23}$. For most carbonaceous materials, $\mathrm{C}=\mathrm{C}$ stretching absorption frequently occurs at this region. The band at $1112 \mathrm{~cm}^{-1}$ is attributing to $\mathrm{C}-\mathrm{O}$ stretching vibrations of functional groups such as alcohols, ethers, carboxylic acids and esters ${ }^{10}$. The result confirms that, the AC contains oxygenated functional groups such as $-\mathrm{OH}$ and $-\mathrm{CO}$ on its surface. Similar results were observed in the $\mathrm{ZnCl}_{2}$ activated Lapsi seed stone carbon ${ }^{4}$.

\section{Result of Boehm titration}

Amount of acidic surface functional groups present carbon surface is shown in Table: 1.

Table 1: Amount of acidic functional groups present in the carbon surface

\begin{tabular}{|l|c|c|c|}
\hline Activated carbon & $\begin{array}{c}\text { Carboxyl group } \\
\text { (meq/gm) }\end{array}$ & $\begin{array}{c}\text { Phenolic group } \\
\text { (meq/gm) }\end{array}$ & $\begin{array}{c}\text { Lactone group } \\
\text { (meq/gm) }\end{array}$ \\
\hline Activated carbon & 0.41 & 1.02 & 0.612 \\
\hline Commercial AC & 0.29 & 1.08 & 0.57 \\
\hline
\end{tabular}


The $\mathrm{H}_{3} \mathrm{PO}_{4}$ activated carbon contains comparatively high concentration of carboxyl, phenolic and lactonic surface functional groups. Thus, $\mathrm{H}_{3} \mathrm{PO}_{4}$ generates more acidic functional groups. The values are also comparable to that of the commercial AC. The higher concentration of acidic functional groups enhances high cation exchange capacity and benefit for the fluoride adsorption. The result of Boehm titration is also supported by FTIR spectra.

\section{Adsorption studies}

Comparison on percentage of fluoride removal by plain $\mathrm{AC}, \mathrm{Al}_{2} \mathrm{O}_{3} / \mathrm{AC}$ composite and $\mathrm{Fe}_{2} \mathrm{O}_{3} / \mathrm{AC}$ composite is shown in Figure: 4.

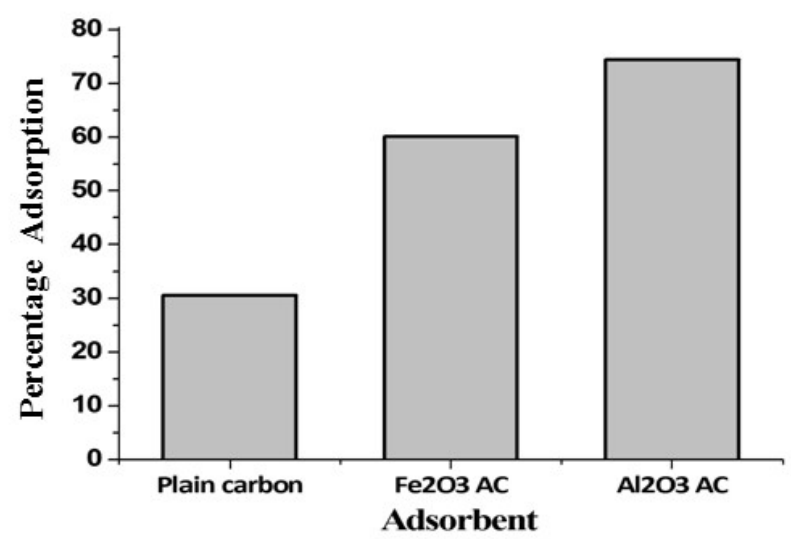

Figure 4: Percentage of fluoride adsorption by plain $\mathrm{AC}, \mathrm{Al}_{2} \mathrm{O}_{3} / \mathrm{AC}$ composite and $\mathrm{Fe}_{2} \mathrm{O}_{3} / \mathrm{AC}$ composite

The plain AC prepared from Supari nut also found to adsorb fluoride from water to certain extent however the fluoride removal capacity is very low. The adsorption capacity is highly increased to by using metal oxide composites. The fluoride adsorption capacity of $\mathrm{Al}_{2} \mathrm{O}_{3} / \mathrm{AC}$ composite was found to be much high higher compared to $\mathrm{Fe}_{2} \mathrm{O}_{3} / \mathrm{AC}$ composite. Thus the composite of $\mathrm{Al}_{2} \mathrm{O}_{3}$ and $\mathrm{AC}$ is much better adsorbent than $\mathrm{Fe}_{2} \mathrm{O}_{3} / \mathrm{AC}$ composite for defluoridation of water. It is assumed that the fluoride adsorption process occurs onto metal oxide composite surface from solution takes place by formation of surface complexes. It can be explained in terms of ligand exchange (surface complex formation) of fluoride on metal oxide/AC composite surface. These metallic cations act as a bridge in between adsorbed fluoride and metal oxide surface. Due to the high capacity of fluoride exchange with hydroxyl ions of the metal oxide composite, fluoride may form metallic fluoride complexes at the adsorbent surface. The fluoride ion exchange reaction involve in the adsorption as follows.

$$
\begin{aligned}
& \equiv \mathrm{M}-\mathrm{OH}_{2}{ }^{+}+\mathrm{F}^{-} \leftrightarrow=\mathrm{M}-\mathrm{F}+\mathrm{H}_{2} \mathrm{O} \\
& \equiv \mathrm{M}-\mathrm{OH}+\mathrm{F}^{-} \leftrightarrow=\mathrm{M}-\mathrm{F}+\mathrm{OH}^{-}
\end{aligned}
$$

( $\equiv \mathrm{M}$ represents the composite surface).

The adsorption capacity of $\mathrm{Al}_{2} \mathrm{O}_{3} / \mathrm{AC}$ composite is higher than $\mathrm{Fe}_{2} \mathrm{O}_{3} / \mathrm{AC}$ composite. This is because the oxidation state of $\mathrm{Al}_{2} \mathrm{O}_{3}$ is higher, which enhances the affinity of $\mathrm{Al}_{2} \mathrm{O}_{3}$ for fluoride as compared to $\mathrm{Fe}_{2} \mathrm{O}_{3}$. In addition to it, aluminum-fluoride complex ions are approximately ten times more stable than corresponding iron (III)-fluoride complex ions ${ }^{24}$. 


\section{J. Nepal Chem. Soc., Vol. 36, 2017}

\section{Conclusions}

In this study, activated carbon was prepared from Supari nut by chemical activation using $\mathrm{H}_{3} \mathrm{PO}_{4}$ as activating agent. Characteristics of activated carbon were studied by $\mathrm{I}_{\mathrm{N}}, \mathrm{MB}_{\mathrm{N}}$, surface area, SEM image and FTIR spectra. The AC showed relatively higher micro-porosity, mesoporosity and high surface area. The porous structure of the AC is also confirmed by SEM image. FTIR spectra indicated that, the activated carbon contains oxygenated functional groups such as $-\mathrm{OH},-\mathrm{CO}$ groups. In accordance with result of the Boehm titration, the AC contains the higher amount of acidic surface functional groups such as carboxyl, phenolic and lactonic. The incorporation of the metal oxide into AC matrix enhanced the fluoride adsorption capacity of the AC. The adsorption studies on the removal of fluoride from water were carried out using $\mathrm{AC}$ composites of $\mathrm{Al}_{2} \mathrm{O}_{3}$ and $\mathrm{Fe}_{2} \mathrm{O}_{3}$ by batch method. High percentage of fluoride adsorption was found in $\mathrm{Al}_{2} \mathrm{O}_{3} / \mathrm{AC}$ composite than $\mathrm{Fe}_{2} \mathrm{O}_{3} / \mathrm{AC}$ composite. Hence, it is concluded that, $\mathrm{Al}_{2} \mathrm{O}_{3}$ / Supari nut $\mathrm{AC}$ composite could be effective alternate adsorbent for removal of fluoride from water.

\section{Acknowledgements}

The author would like to express sincere gratitude to Prof. Dr. Raja Ram Pradhananga, Central Department of Chemistry, Tribhuvan University, Nepal for his support and constructive suggestions throughout the research work. The authors gratefully acknowledges the University Grants Commission for funding this research work.

\section{References}

1. WHO Health criteria and other supporting information, Geneva, World Health Organization, 1984, 2.

2. M.T. Bashir, S.B. Ali, A. Adris and R. Haroon, Asian J. Water Environ. Pollut., 2013, 10, 29.

3. S.P. Kayastha, Int. J. interdiscip. multidiscip. stud. 2015, 3, 2350.

4. R. Rajbhandari, L. K. Shrestha, B. P. Pokharel and R. R. Pradhananga, J Nanosci Nanotechnol, 2013, 13, 2613.

5. G.J. Millar, S.J. Couperthwaite, L.A. Dawes, S. Thompson and J. Spencer, Sep. Purif. Technol., 2017, 187, 14.

6. N.A. Medellin-Castillo, R. Leyva-Ramos, R. Ocampo-Perez, de la C. Garcia, F. Ramon, A. Aragon-Piña, J. M. Martinez-Rosales, R. M. Guerrero-Coronado, L. Fuentes-Rubio, Ind Eng Chem Res., 2007, 46, 9205.

7. K. Biswas, D. Bandhoyapadhyay and U. C. Ghosh, Adsorption, 2007, 13, 83.

8. IUPAC, Manual of Symbols and Terminology for Physicochemical Quantities and Units, Pure Appl. Chem., 1972, 31, 578.

9. A.J. Arulanantham, T.R. Krishna and N.Balasubramanium, Indian J Environ Health, 1989, 13, 531.

10. S.M. Yakout and G. Sharaf El-Deen. Arab. J. Chem, 2016, 9. S1155.

11. J. Hao, T. Lirong, Z. Qiaoling, Z. Xinyu, L. Guanfeng and H. Biao, Scientia Silvae Sinicae, 2011, 47, 147. 
12. S. Lunge, D. Thakre, S. Kamble, N. Labhsetwar and., S. Rayalu, J. Hazard. Mater., 2012, 237, 161.

13. S. Chakrabarty and H. P. Sarma, Pollut. Res. J., 2011, 30, 75.

14. P. Gopalswami, N. Sivakumar, S. Ponnuswamy, V. Venkateswaren and G. Kavitha, J Environ Sci Eng, 2010, 52, 367.

15. A. S. Jadhav and G. T. Mohanraj, Carbon - Sci. Tech., 2016, 8, 132-39.

16. Annual Book of ASTM Standards, ASTM D4607-94, Philadelphia PA, United State of America, 2006.

17. F. Raposo, M.A. De La Rubia and R. Borja, J. Hazard. Mater., 2009, 165, 291-299.

18. N.A. Cleiton and M.C. Guerreiro, Quim Nova, 2011, 34, 472.

19. H. P. Boehm, Carbon, 1994, 32, 759.

20. Thirunavukkarasu O.S. Viraraghavan T. and K.S. Subramanian, Water Air Soil Pollut., 2003, 142, 1 .

21. American Public Health Association (2012), 22nd edition, USA, ISBN 978-087553-013-0.

22. N. Petrova, T. Budinova, M. Razvigorova, E. Ekincib, F. Yardimb and V. Minkova, Carbon, 2000, 38, 2069.

23. A. Allwar, J. appl. chem, 2012, 2, 9.

24. EPA, Environmental Protection agency, Office of solid waste and Emergency Response 1996. 